\title{
TOWARDS A TAXONOMY OF GAMIFICATION DESIGNS FOR BUSINESS MODEL INNOVATION
}

\author{
Stavros Lounis, Katerina Pramatari and Georgios I. Doukidis \\ ELTRUN: The E-Business Research Center, Department of Management Science and Technology, \\ Athens University of Economics and Business. 47A Evelpidon Str. \& 33 Lefkados Str., GR11362, Athens, Greece
}

\begin{abstract}
In an era of gamification and the respective research advances in the field, starting from 2010 a rise is observed in the number of companies introducing a gamification solution in their outlook towards innovation in their business model. We study artefact gamification outcomes of decisions to implement a gamification solution in parallel with the business model the organization operates under found across the literature, in order to identify whether the overarching business model correlates with the type of gamification solution selected for development in the course of their efforts for innovation. Furthermore, we aim to examine the gamification design decisions implemented in selected systems across industries in order to extract valuable input that will help decision makers of companies of similar business models derive to an informed decision relative to their own potential gamification implementation. In this short paper we describe our research approach and recent progress on the utilization of the business models' patterns identified in the St. Gallen's Business Model Navigator ${ }^{\mathrm{TM}}$ in parallel to the Business Model Canvas and to gamification solutions as means to uncover potentially valuable patterns.
\end{abstract}

\section{KEYWORDS}

Business Model Innovation, Gamification, Gamification Systems

\section{INTRODUCTION}

Over the past years gamification has rapidly received the attention of the industry and academia. Since its introduction in the Gartner Hype Cycle in 2011, it has evolved into a standalone industry segment projected to be worth over $\$ 11$ billion by 2020 (Markets and Markets, 2016). A plethora of vendors have spurred that offer one-size-fits-all gamification-as-a-service solutions, by which different organizations (regardless of their core business) can enhance their respective offerings or operations with the introduction of game based affordances (Koivisto \& Hamari, 2019), towards achieving their goals and improving one or more of their business driven gamification goals.

To name but a few, gamified systems have been evangelized to enhance engagement with the end-users be it employees (Dale, 2014; Blohm \& Leimeister, 2013) or customers (Jones et al, 2014; Choi et al., 2014) by providing gameful affordances in various domains like education, employee productivity, customer engagement to name but a few (for a review see Koivisto \& Hamari, 2019). However, academic research, as the field is now starting to mature, still provides little comparable evidence on the gamified systems' results in parallel to the design mainly due to the vastly diverse design of the examined gamified systems and the limited scope posed by the non-game context and the case they are built for. This leaves organizations with having to take uniformed decisions relevant to (a) if they should develop a gamified system, (b) what type of system could they design and in the end (c) will that help them innovate be it in the way the conduct their business or in turn serving value to their respective customers. The aforementioned questions guide this research effort towards identifying and taxonomizing gamification patterns applied in different solutions that operate under the same (or similar) business model, towards enabling decision makers to examine what the competition is doing or force-fit successful solutions of non-competitors both as means to innovate. Chapter 2 presents the gamification grounding, Chapter 3 presents the adopted view on innovation in the business model and lastly Chapter 4 presents the methodology followed in this research. Chapter 5 concludes this short paper by presenting the outlook of the study. 


\section{GAMIFICATION}

Gamification as the "use of game elements in non-game contexts" (Deterding et al., 2011) quickly captured the attention of the industry in less than a decade and is now ever present in our lives as consumers or employers by having transformed a number of systems we use, in gamified activities in order to motivate us to engage with them and enjoy the process.

By utilizing a number of game elements as affordances for gameful experiences like narrative, points, badges and leaderboards among others (for extensive description see Koivisto and Hamari 2019; Pedreira et al. 2015; Seaborn and Fels 2014) companies transform their solutions (or build new ones) with the aim to provide an advanced offering that motivates participants to engage with a solution. In order to design and develop a new gamified solution be it for internal or external use, decision makers have a twofold approach solution (a) to develop the gamified solution from scratch or (b) utilize gamification as a service solutions offered in the market and plug them to their already developed solution. In the case of developing a gamified solution from the ground up decision makers and the respective product team can review other existing solutions in the field served by their competitors and others and derive into a design and development decision and approximately what others are doing and how they could diversify or in the case there are no competitive solutions existing start to develop on their own. In order to do so a number of gamification frameworks are proposed by practitioners and the academy for tailoring the game elements to different non-game contexts, in a way that they can serve different business goals be it business-driven or user-centered. More than 50 gamification frameworks and taxnonomies have been currently proposed (Azouz and Lefdaoui 2018; Mora et al. 2017), however these gamification design frameworks are either too generic or too focused in a non-game context leaving ample room for error or misalignment. The aforementioned is amplified in the case of utilizing an already developed and offered gamification-as-a-service solution where the interested company can utilize a third party service offering the ability to "plug in" features enabling point awarding, leaderboards, badges authoring etc. to their solution due to the lack of detailed guidance and academic answers behind the question of "Why and how should I employ game element X". The answer to the aforementioned and the overall introduction of gamification to the core of a business should derive from informed decisions that are parallel to the general objectives and direction of the company and on that account it should be parallel and complementary to its business model.

\section{BUSINESS MODEL INNOVATION}

In the centre of every organization exists the rational and way of how it "creates, delivers and captures value" (Osterwalder and Pigneur, 2010 p14) i.e.. its Business Model. Originating from the dot com era where the need to effectively and efficiently describe an entrepreneurial Internet related idea to potential investors occurred, the Business Model, not only maintained relevance as the years passed, but has become a pivotal descriptor of any organization. Business Models have also gained academic ground and several definitions have been proposed (for review see Massa et al.,2017; George and Bock, 2011; Zott et al., 2011) most of which have the common denominators of including categories relevant to value proposition, value capture - creation - delivery (Richardson, 2008) and value networks (Zott \& Amit, 2010).

As Business Models evolve, academics have proposed and evaluated several frameworks (e.g. Business Model Framework by Chesbrough, 2007) and tools (e.g. Business Model Canvas by Osterwalder, 2005) that can assist practitioners in understanding, decomposing, depicting and ultimately evolving their (an) organizations' business model. A prominent tool for business modelling is the "Business Model Canvas" (Osterwalder et al., 2005; Osterwalder and Pigneur, 2009). The Business Model Canvas (BMC) with its nine elements (i.e. Key partners, Key activities, Key resources, Cost Structure, Value proposition, Customer segments, Customer relationships, Channels and Revenue streams) can depict and present the key points relevant to the current Business Model of an organization as well as be utilized for experimentation in differentiation to competition and future business model design. As nowadays the Business Model is at the epicentre of each organization, efforts are constantly conducted on the account to differentiate and innovate.

The focal point of managers and decision makers remains with the opportunity to make "business model replacements that provide product or service offerings to customers and end users that were not previously available" (Mitchel and Coles, 2003) termed as Business Model Innovation and its accompanying process. 
Previous work has highlighted that Innovation can become Business Model Innovation "when two or more elements of a business model are reinvented to deliver value in a new way." (Lindgardt et al.,2009). In order to innovate in their Business Model, companies can therefore utilize the Business Model Canvas and explore different alterations to the current status of each element (and changes in more than one) towards exploring new Business Model formations. However as the possibilities of change in any given element of a Business Model is inherently complex and with a plethora of potential options a starting point is needed. In their seminal work, Gassmann, O., Csik, M., Frankenberger, K (2012) after analysing 250 business models applied in different industries during the past 25 years identified 55 distinct patterns (Table 1) of business models and proposed the Business Model Navigator ${ }^{\mathrm{TM}}$ (Gassmann, Frankenberger and Csik, 2013) as means to support Business Model Innovation. The Business Model Navigator ${ }^{\mathrm{TM}}$ as a tool for business model innovation is utilized in the ideation phase of the innovation journey by the decision makers. After the identification of the current operational Business Model, with the use of the different patterns a force fit of a pattern (or a combination) is examined. For example, if the current Revenue Stream of a Business Model is [12.] Direct Selling, what could be done by changing it to [15.] Flat Rate etc.

Table 1. The St. Gallen 55 Business Model Patterns (adapted from Gassmann, Frankenberger and Csik, 2013)

\begin{tabular}{llll}
\hline & \multicolumn{2}{c}{ The 55 Business Model Patterns } \\
\hline 1. Add-on & 17. Franchising & 33. Open Source & 49. Supermarket \\
2. Affiliation & 18. Freemium & 34. Orchestrator & 50. Target the poor \\
3. Aikido & 19. From Push to Pull & 35. Pay per use & 51. Trash to cash \\
4. Auction & 20. Guaranteed Availability & 36. Pay what you want & 52. Two Sided Market \\
5. Barter & 21. Hidden Revenue & 37. Peer to Peer & 53. Ultimate Luxury \\
6. Cash machine & 22. Ingredient Branding & 38. Performance contracting & 54. User Designed \\
7. Cross selling & 23. Integrator & 39. Razor and Blade & 55. White Label \\
8. Crowdfunding & 24. Layer Player & 40. Rent Instead of Buy & \\
9. Crowdsourcing & 25. Leverage Customer Data & 41. Revenue Sharing & \\
10. Customer Loyalty & 26. License & 42. Reverse Engineering & \\
11. Digitization & 27. Lock - In & 43. Reverse Innovation & \\
12. Direct Selling & 28. Long Tail & 44. Robin Hood & \\
13. E-Commerce & 29. Make More of It & 45. Self-Service & \\
14. Experience Selling & 30. Mass Customization & 46. Shop-in-Shop & \\
15. Flat Rate & 31. No Frills & 47. Solution Provider & \\
16. Fractional Ownership & 32. Open Business Model & 48. Subscription & \\
\hline
\end{tabular}

\section{TOWARDS INTERSECTING BUSINESS MODELS AND GAMIFICATION}

The provision of a new gamified system by an organization instantly classifies as a Business Model Innovation, as there is a business model replacement in one or more elements (e.g. value proposition) as the product or service offering to the end users was not previously available (Mitchel and Coles, 2003). However, currently there is no information or guidance on (a) which parts of the business model are affected by that change or (b) what type of gamification would / could an organization employ in terms of what the competition is doing (similar business model) or what other industries are doing respectively for completely different Business Models. The goal of this research is to cross-reference previous academic findings as well as business best practices in different fields and examine existing gamification solutions for different Business Model patterns. In turn having classified the different extant gamification solutions a secondary analysis will enable us to identify which of the Business Model Canvas elements are mostly affected by a possible introduction of gamification in the Business Model of a current organization. Table 2 presents an outcome of this ongoing study where two different gamification examples have been classified initially based on the predominant business model pattern from the Business Model Navigator they adhere to (Auctioning and Performance contracting respectively) and both our examples of new potential revenue streams. 
Table 2. Indicative example of the taxonomy of game elements to Business Model elements

\begin{tabular}{cccl}
\hline BM Component & St. Gallen BMN ${ }^{\mathrm{TM}}$ & Gamification Examples & Game elements \\
\hline Revenue Streams & 4. Auction & $\begin{array}{c}\text { Mordor of Warsaw } \\
\text { (Olszewski et al. 2018) }\end{array}$ & $\begin{array}{l}\text { Points, Trophies, } \\
\text { Leaderboard }\end{array}$ \\
& 38. Performance Contracting & $\begin{array}{c}\text { ChArGED (Kotsopoulos et } \\
\text { al., 2018) }\end{array}$ & $\begin{array}{l}\text { Avatar, Points, } \\
\text { Badges, Leaderboard, } \\
\text { Team collaboration }\end{array}$ \\
\hline
\end{tabular}

\section{CONCLUSION}

This short paper presents the ongoing research aimed at taxonomizing game design guidelines and game elements found across the academic literature as well as business best practices in the field in parallel to the business model patterns the extant solutions operate under. The introduction of gamification into an organization should be driven by its strategic objectives first and foremost and also be aligned with its business model (current or new). The aforementioned is often neglected by organizational technology decision makers and upon completion, this research aims to enable senior executives in the process of business model innovation, through the introduction of a gamification solution, to have a guide that will present them with information relevant to (a) existing gamification approaches already available in their respective business model pattern - ergo competition, and (b) existing gamification approaches available in a different business model pattern they are exploring - ergo differentiation potential. Lastly and with the introduction of Business Model Canvas elements, decision makers will have an initial view on what part of their business model will be more affected by a proposed introduction of gamification towards business model innovation.

\section{ACKNOWLEDGEMENT}

This research was funded by the Athens University of Economics and Business Support Program "Action 2: Support to postdoctoral researchers".

\section{REFERENCES}

Azouz, O., \& Lefdaoui, Y., 2018. Gamification design frameworks: A systematic mapping study. In International Conference on Multimedia Computing and Systems-Proceedings, Vol. 2018 - May, pp. 1-9.

Blohm, I., and Leimeister, J. M., 2013. Gamification: Design of it-based enhancing services for motivational support and behavioral change. Business \& Information Systems Engineering, Vol. 5 No 4, pp. 275-278.

Chesbrough, H., 2007. Business model innovation: it's not just about technology anymore. Strategy \& Leadership, Vol 35 No 6, pp. 12-17, Emerald Group Publishing Limited.

Choi, J. et al., 2014. A study about designing reward for gamified crowdsourcing system. Proceedings of 3rd International Conference on Design, User Experience, and Usability: User Experience Design for Diverse Interaction Platforms and Environments pp. 678-687.

Dale, S., 2014. Gamification: Making work fun, or making fun of work? Business Information Review, 31(2), pp. 82-90.

Deterding, S. et al., 2011. From Game Design Elements to Gamefulness: Defining "Gamification". MindTrek'11, September 28-30, Tampere, Finland.

Gassmann, O. et al., 2013. The St.Gallen Business Model Navigator. BMI lab, Institute of Technology Management, University of St. Gallen.

Gassmann, O. et al., 2012.Aus alt mach neu. Harvard Business Manager, June 2012.

George, G., and Bock, A. J. 2011. The Business Model in Practice and its Implications for Entrepreneurship Research. Entrepreneurship Theory and Practice, Vol. 35, No 1, pp. 83-111.

Koivisto, J. and Hamari, J., 2019. The rise of motivational information systems: A review of gamification research. International Journal of Information Management. Vol. 45, April 2019, pp. 191-210. 
Kotsopoulos, D. et al., 2018. Employee Profiles and Preferences towards Workplace Gamification for Energy Conservation. International Journal of Serious Games, Vol 5, No 2, pp. 65 - 85.

Jones, B. A. et al., 2014. The FIT game: Preliminary evaluation of a gamification approach to increasing fruit and vegetable consumption in school. Preventive Medicine, Vol. 68, pp. 76-79.

Lindgardt, Z. et al., 2009. Business Model Innovation. When the Game Gets Tough, Change the Game. The Boston Consulting Group, Boston.

Markets and Markets 2016. Gamification Market by Solution (Consumer driven and Enterprise driven), Applications (Sales and Marketing), Deployment Type (On-Premises and Cloud), User Type (Large Enterprise, SMBs), Industry and Region - Global Forecast to 2020. February 2016, Report Code: TC1445. http://www.marketsandmarkets.com/Market-Reports/gamification-market-991.html

Massa, L. et al., 2017 A Critical Assessment of Business Model Research. ANNALS, Vol 11, pp. 73-104

Mitchell, D. and Coles, C.. 2003. The ultimate competitive advantage of continuing business model innovation. Journal of Business Strategy, Vol. 24 No. 5, pp. 15-21.

Mora, A. et al., 2017. Gamification: A systematic review of design frameworks. Journal of Computing in Higher Education,.Vol. 29, pp. 516-548.

Olszewski, R. et al., 2018. Solving "Smart City" Transport Problems by Designing Carpooling Gamification Schemes with Multi-Agent Systems: The Case of the So-Called "Mordor of Warsaw". Sensors, Vol. 18, No 1 p.141.

Osterwalder, A. et al., 2005. Clarifying business models: origins, present, and future of the concept. Communications of the Association for Information Systems, Vol 15, No 1, pp 1-25.

Osterwalder, A. and Pigneur, Y., 2009. Business Model Generation: A Handbook for Visionaries, Game Changers, and Challengers. John Wiley \& Sons. Hoboken.

Osterwalder, A. and Pigneur, Y., 2010. Business Model Generation. Wiley \& Sons, Hoboken.

Richardson, J. 2008. The business model: an integrative framework for strategy execution. Strategic Change, Vol. 17 No 5-6, pp. 133-144.

Seaborn, K., and Fels, D. I. 2014. Gamification in theory and action: A survey. International Journal of Human-Computer Studies, Vol 74, pp. 14-31.

Zott, C., and Amit, R., 2010. Business Model Design: An Activity System Perspective, Long Range Planning, Vol. 43, Issues 2-3, pp. 216-226.

Zott, C. et al., 2011. The Business Model: Recent Developments and Future Research. Journal of Management, Vol. 37, No. 4, pp. 1019-1042. 